\title{
Aspectos culturais revelados pela análise léxico-semântica da unidade lexical pantaneiro
}

\author{
Beatriz Aparecida Alencar \\ Universidade Federal de Mato Grosso do Sul (UFMS), Três Lagoas, Mato Grosso do Sul, Brasil \\ Instituto Federalde Mato Grosso do Sul (IFMS), Aquidauana, Mato Grosso do Sul, Brasil ${ }^{1}$ \\ bia83_12@hotmail.com
}

DOI: $\underline{\text { http://dx.doi.org/10.21165/el.v45i1.773 }}$

\begin{abstract}
Resumo
Este trabalho realiza um estudo léxico-semântico sobre a unidade léxica pantaneiro que nomina o homem típico do oeste de Mato Grosso do Sul e Mato Grosso, com o objetivo de examinar a relação entre léxico e ambiente, bem como apontar aspectos culturais revelados pela análise léxico-semântica do item lexical pantaneiro destacando sua relevância regional. A análise pautou-se em dados fornecidos pelo verbete pantaneiro de dicionários da língua portuguesa produzidos nos séculos XVIII, XIX, XX e XXI; de obras lexicográficas de cunho regional e da Tese de Doutorado A linguagem do homem pantaneiro (NOGUEIRA, 1989). O estudo demonstrou a relação léxico-ambiente, apontando aspectos culturais revelados pela análise do item lexical pantaneiro, cujas acepções revelam o vínculo entre o homem e a localidade, com as relações de trabalho e com o sentimento de pertença à região do Pantanal.
\end{abstract}

Palavras-chave: léxico; pantaneiro; cultura.

\section{Aspectos culturales revelados por el análisis léxico-semántico de la unidad lexical pantaneiro}

\section{Resumen}

En este trabajo, se realiza un estudio léxico-semántico sobre la unidad lexical del Pantanal que nombra el hombre típico del oeste de Mato Grosso do Sul y Mato Grosso, con el objetivo de examinar la relación entre léxico y ambiente, así como señalar los aspectos culturales revelados por el análisis del ítem lexical pantaneiro, con destaque de su importancia regional. El análisis fue basado en los datos fornecidos por la entrada del vocablo pantaneiro en los diccionarios de la Lengua Portuguesa (XVIII, XIX, XX e XXI); de las obras lexicográficas de carácter regional y de la tesis doctoral A linguagem do homem pantaneiro (NOGUEIRA, 1989). El estudio demostró la relación léxico-ambiente, apuntando aspectos culturales revelados por el análisis del ítem lexical "pantaneiro", cuyas acepciones presentan el vínculo entre el hombre con el espacio, con las relaciones de trabajo y con el sentimiento de pertenecer a la región analizada.

Palabras clave: léxico; pantaneiro; cultura.

\footnotetext{
${ }^{1}$ Doutoranda no Programa de Pós-Graduação em Letras da Universidade Federal de Mato Grosso do Sul e docente efetiva do Instituto Federal de Mato Grosso do Sul.
} 


\section{Primeiras palavras}

Este texto discute resultados de estudo realizado acerca do item lexical pantaneiro que designa o morador nativo do Extremo Oeste dos Estados de Mato Grosso e de Mato Grosso do Sul, na divisa com a Bolívia e com o Paraguai. Para isso, primeiramente, descrevemos o perfil do pantaneiro, homem típico da região, e tecemos considerações sobre o seu habitat, o Pantanal, com vistas a caracterizar tanto o ser humano quanto a natureza enquanto representantes do mesmo cenário/conjunto, além de recuperar fatos importantes acerca da história da localidade.

$\mathrm{Na}$ sequência, analisa-se a unidade lexical pantaneiro com base em dados fornecidos pelas seguintes obras: i) dicionários gerais da língua portuguesa - Bluteau (1712-1728); Moraes Silva (1813); Silva Pinto (1832); Figueiredo (1899); Freire (1940); Houaiss (2001); Aulete (2006); Ferreira (2010); Borba (2004); ii) dicionários regionais - Souza (1939); Ortêncio (1983) e iii) a Tese de Doutorado, pioneira nos estudos do léxico da região do Pantanal, A linguagem do homem pantaneiro (NOGUEIRA, 1989).

Buscamos, com este estudo, examinar a relação entre léxico e ambiente, na perspectiva dos estudos de Sapir (1969), bem como apontar aspectos culturais revelados pela análise léxico-semântica do item lexical pantaneiro. Além disso, analisamos as acepções da unidade léxica investigada e sua relevância no panorama regional.

\section{Pantaneiro: o morador típico do Pantanal sul-mato-grossense e sua cultura}

O pantaneiro, morador típico do Pantanal, além de representar a presença humana no ambiente, também auxilia na sobrevivência do próprio ecossistema. $\mathrm{O}$ peão pantaneiro é produto da criação dos grandes latifúndios e do povoamento da fronteira oeste. A ocupação do território pelo não índio no Pantanal ocorreu praticamente em fins do século XIX, sobretudo após a Guerra da Tríplice Aliança (1864-1870), quando a pecuária passa a ser intensificada na fronteira oeste: "Após a Guerra do Paraguai, a pecuária se desenvolveu de forma acelerada na região do Pantanal, com o rebanho aumentado de forma rápida, permitindo a formação de vastas fazendas de criação" (GARCIA, 2009, p. 76).

Tradicionalmente, os pantaneiros permaneceram em contato com a lida do campo, voltada essencialmente para as tradições da pecuária de corte. Porém, ao tratarmos do homem pantaneiro e de sua linguagem, precisamos considerar o contexto sócio-histórico em que esse homem está inserido, como o isolamento dos centros urbanos, o baixo nível de escolaridade, a vivência com um universo predominante do sexo masculino, o contato intenso com o ambiente rural, alguns com menor mobilidade e outros transitando entre as fazendas da região.

Em termos culturais o homem pantaneiro configura-se como um indivíduo constituído também pelas relações com o ambiente, já que o "homem que habita essa realidade, seus utensilios e práticas rurais, enfim, seu modo de viver, adaptado à realidade rural dos pantanais, evidencia o processo harmônico de interação entre homem e natureza" (NOGUEIRA, 2002, p. 28). 
Essa interação também se reflete na caracterização do homem e do habitat pantaneiro, como descreve Nogueira (2002, p. 20):

[...] o distanciamento dos núcleos urbanos; o relativo isolamento, agravado pelas deficiências das vias de acesso a muitas fazendas; a vizinhança com dois países latinoamericanos, o Paraguai e a Bolívia; a situação de oposição dos elementos, que mantêm o equilibrio, através dos contrastes, como: contraste natural entre as grandes enchentes e os prolongados estios; contraste socioeconômico entre o patrão e o peão; contraste demográfico entre os pequenos aglomerados em torno das sedes das fazendas e o vazio das léguas desabitadas.

Esses elementos fizeram com que o homem pantaneiro tivesse que adaptar a sua rotina às características do meio ambiente: objetos, utensilios, modos de viver, contato com o imprevisível por conta das enchentes, e também, em tempos mais antigos, pelos possíveis ataques dos povos indígenas "que não se conformavam com a invasão de seus territórios” (NOGUEIRA, 2002, p. 21).

Nesse contexto, é preciso também considerar a questão do domínio indígena no território em causa, pois houve nessa região uma das maiores tentativas de proteção de terras por parte dos nativos, uma vez que o "pantanal sul-mato-grossense foi palco da maior e mais obstinada cena de oposição sistemática à presença colonizadora da história do Brasil"' (MARTINS, 2002, p. 14).

Além dessas dificuldades elencadas, a dificuldade de transporte em virtude da precariedade das vias de comunicação fez com que o homem pantaneiro produzisse alimentos para o consumo, já que alguns produtos não chegavam ou tardavam a chegar à região. Dessa forma, o pantaneiro se transformou, segundo Nogueira (2002), em um "criativo improvisador" para suprir as necessidades imediatas que o meio não oferecia aos seus habitantes.

É inquestionável que essas necessidades fizeram com que o ambiente e o ser humano se aproximassem e realizassem uma simbiose, já que, no contexto pantaneiro, indivíduo e localidade têm suas histórias guiadas pelo ciclo das águas, protegidos pela natureza e pela sua localização geográfica. Todas essas características contribuem para a manutenção de uma relação indissociável entre os costumes, a cultura e a linguagem do pantaneiro. Dessa forma, para entendermos melhor o universo pantaneiro não podemos desvincular a cultura da linguagem, pois estudar a língua, sobretudo o léxico, é também pesquisar sobre a cultura de um determinado povo/região:

Partindo-se do princípio de que investigar uma língua é investigar também a cultura, considerando-se que o sistema lingüístico, nomeadamente o nível lexical, armazena e acumula as aquisições culturais representativas de uma sociedade, o estudo de um léxico regional pode fornecer, ao estudioso, dados que deixam transparecer elementos significativos relacionados à história, ao sistema de vida, à visão de mundo de um determinado grupo. Deste modo, no exame de um léxico regional analisa-se e caracteriza-se não apenas a língua, mas também o fato cultural que nela se deixa transparecer. Essa perspectiva de análise favorece uma melhor compreensão do próprio homem e da sua maneira de ver e de representar o mundo (ISQUERDO, 2001, p. 91).

Nessa perspectiva, para a análise da unidade lexical pantaneiro torna-se necessário caracterizar o ambiente, compreender quem é o indivíduo e o ecossistema que compõem a região, quais os primeiros registros realizados sobre a localidade, entre 
outros aspectos. Passemos, pois, à contextualização da região em que se localiza o Pantanal.

\section{Pantanal sul-mato-grossense: contextualização da região}

O Pantanal se constitui, geograficamente, em "uma extensa planície de acumulação, com topografia plana e alagada periodicamente, tendo o rio Paraguai e seus afluentes como o principal meio de transporte de água e sedimentos" (SOUZA; LANI; SOUSA, 2006, p. 10). Em termos de localização, abrange parte de dois estados brasileiros: o Mato Grosso e o Mato Grosso do Sul e, além disso, também atinge terras no norte do Paraguai e no Leste da Bolívia. Boa parte do Pantanal brasileiro pertence ao estado do Mato Grosso do Sul. A região recebe subdivisões territoriais distintas, como a apresentada na figura 1 que contém 11 sub-regiões:

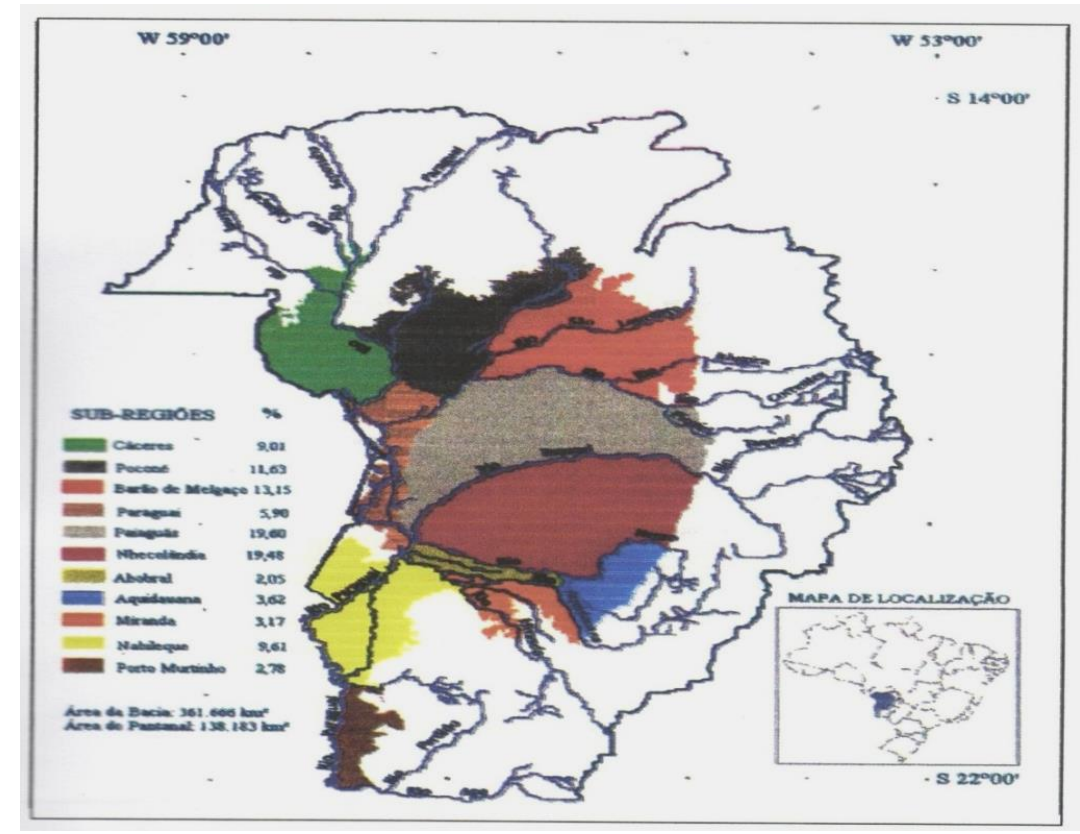

Figura 1. Localização do Pantanal brasileiro e respectivas subdivisões

Fonte: Silva; Abdon (1998, p. 1705)

Para a divisão das sub-regiões de Cáceres, Poconé, Barão do Melgaço, Paraguai, Paiaguás, Nhecolândia, Abobral, Aquidauana, Miranda, Nabileque e Porto Murtinho que figuram no mapa, os autores "[...] adotaram como critérios de caracterização dos pantanais: a inundação, relevo, solo e vegetação" (SILVA; ABDON, 1998, p. 1710).

\section{Pantanal: primeiros registros sobre o nome da localidade}

A obra História de um país inexistente (COSTA, 1999), por exemplo, traz referências antigas sobre a região com base em narrativas de viajantes que cruzaram a região do Pantanal entre os séculos XVI e XVIII, dentre eles, Ulrico Schmidl, Alvar Núñez Cabeza de Vaca e Ruy Díaz de Guzmán. Para esses viajantes, o espaço 
pantaneiro era utilizado como local de passagem, por isso "não ganhou uma narrativa substantivamente sua; seus relatos quase sempre estão contidos em descrições de viajantes que por variados motivos tinham de cruzar seus rios como caminhos que os levassem a outras partes" (COSTA, 1999, p. 63).

Nos relatos reproduzidos na obra em questão, a região do pantanal é descrita como um lugar com características que misturam a realidade e ficção. O espaço é apresentado "ao mesmo tempo hostil, fantástico e paradisíaco. Lugar de homens, animais e ambientes totalmente estranhos. Sua paisagem é algo indefinível. O equilibrio entre secas e cheias desfigura os contornos da paisagem e cria uma geografia móvel" (COSTA, 1999, p. 64).

É importante considerar que, durante esse período colonial, havia pouco conhecimento sobre a região pantaneira, o que propiciava a descrição das localidades de modo mitológico, porém, devemos ressaltar que com os relatos dos viajantes é que "pela primeira vez os habitantes, as águas dos rios e lagos, a flora, a fauna e o relevo daquele lugar foram levados à linguagem escrita" (COSTA, 1999, p. 64).

A região na atualidade denominada como Pantanal recebeu, inicialmente (século XVII), a designação de Laguna de los Xarayes, "lugar de grandes águas entrecortadas por muitos rios e habitado por milhares de indígenas" (COSTA, 1999, p. 17), habitado, dentre outras, pela etnia indígena Xarayes. A partir de 1615, com a obra Historia general de los hechos castellanos en las islas y tierra-firme del mar océano, de Antonio de Herrera, a região passou a ser assim reconhecida e inscrita na geografia das conquistas espanholas.

O nome Pantanal surgiu em meados do século XVIII e foi atribuído aos monçoeiros que ampliavam os domínios portugueses:

A denominação foi dada pelos portugueses do Brasil, os monçoeiros. Estes, seguindo as rotas abertas pelos bandeirantes paulistas, avançaram além dos limites fixados em 1494 em Tordesilhas e, no início dos anos setecentos, fizeram daquelas águas seu caminho às terras conquistadas. Desconhecendo a Laguna de los Xarayes e a geografia castelhana, ao chegarem à planície inundável da bacia do Alto Rio Paraguai, denominaram-na Pantanais; segundo definiram, 'são campos alagados, com várias lagoas e sangradouros' (COSTA, 1999, p. 19).

Em relação às designações atribuídas à região, é possível pontuar que os diferentes nomes para o local acompanham a própria história social da localidade, recebendo o nome de Laguna de los Xarayes, enquanto território espanhol, e Pantanal, após o conhecimento do território pelos portugueses ${ }^{2}$. O quadro 1 , na sequência, traz uma síntese das nomeações e as respectivas características atribuídas para a região que as motivaram:

Quadro 1. Designações Laguna de los Xarayes e Pantanal: contextualização

\begin{tabular}{|l|l|}
\hline \multicolumn{1}{|c|}{ Laguna de los Xarayes } & \multicolumn{1}{c|}{ Pantanal } \\
\hline Es panhol & Português \\
\hline Visão mítica & Visão objetiva \\
\hline Atração dos colonizadores & Rota de passagem \\
\hline \multicolumn{2}{|c|}{ Ponto em comum: área alagada } \\
\hline
\end{tabular}

De acordo com o quadro 1, é possível notar que as designações atribuídas à região traduzem a visão do homem sobre o espaço nomeado, ou seja, o olhar dos

\footnotetext{
${ }^{2}$ A esse respeito, confira Isquerdo (2006).
} 
colonizadores sobre as terras pantaneiras, tendo como ponto em comum a descrição do local como área alagada.

Além disso, é evidente que a cultura portuguesa foi decisiva no processo de nomeação da região, como pondera Isquerdo (2006, p. 129-130): “[...] instaura-se o novo designativo, o hidrotopônimo Pantanal, um termo mameluco que evidencia a supremacia do domínio português sobre aquelas terras".

A discussão sobre o nome da região buscou auxiliar na análise sobre a origem da unidade léxica pantaneiro, já que a unidade léxica pantanal é anterior à designação do homem e/ou animal que habita a região, como demonstrado pelos dados registrados nas obras lexicográficas consultadas.

\section{A unidade lexical pantaneiro: registro e análise dos dados}

\subsection{Presença nas obras lexicográficas}

A unidade lexical pantaneiro figura no $\operatorname{VOLP}^{3}$ (Vocabulário Ortográfico da Língua Portuguesa) e é classificada como adjetivo e substantivo masculino. Além disso, está presente nos dicionários de Figueiredo (1899), Freire (1940), Houaiss (2001), Borba (2004), Ferreira (2010) e Aulete (2006), bem como na tese de Nogueira (1989) no dicionário de Ortêncio (1983).

Tendo em vista a particularidade da unidade lexical estudada, salientamos a presença do item lexical pantaneiro na tese de Nogueira (1989) que inicia os estudos sobre a linguagem dos habitantes do Pantanal. Essa autora define a forma pantaneiro como: "Adj. 1. Habitante do Pantanal, o criador de gado nos pantanais. 2. Raça de gado crioulo do Pantanal; 3. Cavalo pantaneiro (P1 a P4). "U povu pantaneru aqui ar veiz chega um aí cunvida eli" (P1). "Gora u gadu, essi gadu pantaneru (P4-6)".

Por sua vez, ao consultarmos as demais obras lexicográficas, tais como a de Bluteau (1712-1728), de Silva Pinto (1832), de Moraes Silva (1813), disponíveis em: <www.brasiliana.usp.br>, nota-se a ausência do verbete pantaneiro. No entanto, esses dicionários registram a entrada pantanal e seus derivados, como pode ser observado no quadro 2, a seguir.

Quadro 2. Registro da unidade léxica pantanal em dicionários dos séculos XVIII e XIX

\begin{tabular}{|l|l|}
\hline \multicolumn{1}{|c|}{ Dicionários } & \multicolumn{1}{c|}{ Entradas e acepções } \\
\hline Bluteau (1712-1728) & $\begin{array}{l}\text { Pântano: Grande e profundo atoleiro. } \\
\text { Pantanoso: Apaulado. Cheio de lagoas. }\end{array}$ \\
\hline Silva Pinto (1832) & $\begin{array}{l}\text { Pantana: s.f. V. Pantano. } \\
\text { Pantanal: s.m. Grande atoleiro. } \\
\text { Pantano: s.m. Grande atoleiro. } \\
\text { Pantanoso: adj. Onde há pantano, apaulado. }\end{array}$ \\
\hline Moraes Silva (1813) & $\begin{array}{l}\text { pantanal: s.m. Atoleiro espaçoso. } \\
\text { pantano: s.m. Atoleiro, lamarão molle, tremedal, que sorve as coisas pesadas. } \\
\text { pantanoso: adj. Em que há pantano, ou atoladiço como o pantano, apaulado. }\end{array}$ \\
\hline Figueiredo (1889) & "s.m. Bras. Boi de certa raça de Mato Grosso". \\
\hline
\end{tabular}

3 Consulta realizada no endereço eletrônico: <http://www.academia.org.br/nossa-lingua/busca-novocabulario>. Acesso em: 02 mar. 2015. 
De acordo com o quadro 2, percebe-se que a unidade lexical pantaneiro não se configura como um item lexical muito antigo na língua, pois não figura em nenhuma das obras examinadas que integram o quadro. De modo semelhante, pontua-se a ausência da unidade lexical pantaneiro no Dicionário Etimológico Nova Fronteira (CUNHA, 1986) e no Dicionário de Etimologias de Língua Portuguesa (GUÉRIOS, 1979). Na primeira obra, há a presença do verbete pântano enquanto na segunda aparecem pântano e pantanal.

Houaiss (2001), por sua vez, registra meados do século XVIII como data do surgimento da unidade lexical pantanal:

PANTANAL: s.m. (1789 cf $\mathrm{MS}^{1}$ ) 1. Grande extensão de pântano. 2 GEO zona geofísica que constitui um dos mais importantes ecossistemas do Brasil; é a maior planície inundável do planeta, com uma área de cerca de $120 \mathrm{mil} \mathrm{km}^{2}$ que abrange o Sudoeste de Mato Grosso, o Oeste de Mato Grosso do Sul e parte do Paraguai. Inic. Maiúsc. Etim. pântano+al SIN/VAR de lodaçal (HOUAISS, 2001, p. 2119).

Nota-se que a definição faz menção apenas às características geográficas da localidade nomeada. Já a unidade léxica pantaneiro é mais recente. De acordo com Houaiss (2001), surge apenas no século XX. O quadro 3, que segue, registra as acepções registradas no verbete pantaneiro em dicionários gerais contemporâneos (séculos XX e XXI).

Quadro 3. Registro da unidade léxica pantaneiro em dicionários gerais (séc. XX e XXI)

\begin{tabular}{|c|c|}
\hline Dicionários & Acepções \\
\hline Freire (1940) & "Adj. Raça de gado cuiabano; s.m. Boi de certa raça de Mato Grosso". \\
\hline Houais s (2001) & $\begin{array}{l}\text { "adj.sm. (sXX) B 1. relativo a pântano, esp. Ao Pantanal mato-grossense, ou o que } \\
\text { é seu natural ou habitante (espécimes p.) (um p. da gema). s.m. MT MS 2. criador } \\
\text { de gado; fazendeiro 3. BEI indivíduo ocioso e dado a vulgaridades e gracejos. Adj } \\
\text { Zoot MT MS } 4 \text { diz-se de uma raça bovina mato-grossense. ETM: pântano+eiro". }\end{array}$ \\
\hline Borba (2004) & $\begin{array}{l}\text { "Adj } 1 \text { do ou relativo ao Pantanal Mato-grossense: onça pantaneira. Sm } 2 \text { quem cria } \\
\text { gado no Pantanal Mato-grossense: Como o sertanejo, o pantaneiro é um forte". }\end{array}$ \\
\hline Aulete (2006) & $\begin{array}{l}\text { "s.m.1. Indivíduo que nasceu ou vive no Pantanal. } \\
\text { 2. MS MT Aquele que cria gado; FAZENDEIRO (a). } \\
\text { 3. Do pantanal mato-grossense; típico dessa região ou de seu povo. } \\
\text { 4. Relativo a pântano (animal pantaneiro). [F.: pântano + -eiro.]". }\end{array}$ \\
\hline Ferreira (2010) & $\begin{array}{l}\text { "adj. (Bras. MT) Adj 1. Diz-se de uma raça bovina mato-grossense, 2. s.m. (Bras. } \\
\text { Mato Grosso) criador de gado, fazendeiro". }\end{array}$ \\
\hline
\end{tabular}

Além do registro da unidade lexical pantaneiro nos dicionários gerais da língua portuguesa contemporâneos, buscamos esse verbete também em dicionários de cunho regional, tendo em vista a relação semântica existente entre o ambiente e o homem típico da região. Portanto, o quadro 4, na sequência, traz as acepções para pantaneiro, constantes nesse tipo de dicionário. 
Quadro 4. Registro da unidade léxica pantaneiro em dicionários regionais (séc. XX)

\begin{tabular}{|l|l|}
\hline \multicolumn{1}{|c|}{ Dicionários } & \multicolumn{1}{c|}{ Acepções } \\
\hline Souza (1939) & $\begin{array}{l}\text { "Com êste nome se designa uma variedade de gado vacum próprio do pantanal de } \\
\text { Mato Grosso, registrando-o Cândido de Figueiredo. Encontramo-lo, porém, } \\
\text { empregado no sentido de criador da mesma região, fazendeiro, num artigo de A. de } \\
\text { P. Leonardo Pereira, publicado no O Jornal de 23 de setembro de 1928, no seguinte } \\
\text { passo: 'O pantanal mato-grossense não tem rival. E quando o pantaneiro em lugar } \\
\text { de deixar seu rebanho ao léu do tempo, com um inverno excessivamente frio, de } \\
\text { três a oito graus abaixo de zero, causado pelo degê-lo dos Andes, muito terá feito } \\
\text { em prol de sua indústria...". }\end{array}$ \\
\hline Ortêncio (1983) & $\begin{array}{l}\text { "v. Citações: "Pantaneiro - Variedade de gado bovino, característico da zona do } \\
\text { Pantanal, em Mato Grosso". E. S. Bruno, 156, HB. "O restante dos cuidados } \\
\text { confiavam à natureza providente, que entrou a atuar de maneira acentuada, } \\
\text { expressa na variedade pantaneira, de couro grosso, resistente às intempéries e aos } \\
\text { mosquitos e afeita à luta contra as águas, em que vive grande parte do ano". V.C. } \\
\text { Fonseca, 112, PM". }\end{array}$ \\
\hline
\end{tabular}

A consulta às diferentes obras lexicográficas citadas (antigas, contemporâneas, regionais) permite-nos tecer as seguintes considerações:

$\checkmark$ referência à região Centro-Oeste por meio das marcas dialetais MS e/ou MT em várias definições;

$\checkmark$ ocorrência da unidade lexical pantaneiro classificada gramaticalmente como adjetivo ou substantivo;

$\checkmark$ presença das diferentes marcas de uso da designação pantaneiro, inclusive expressando julgamento de valor.

$\mathrm{Na}$ sequência, discutimos aspectos identificados com base na análise da unidade léxica pantaneiro nos dicionários consultados.

\subsection{Marcas de regionalismo}

A unidade lexical pantaneiro recebe marca dialetal nos dicionários Houaiss (2001), Borba (2004), Aulete (2006) e Ferreira (2010), que apresentam a informação de que a unidade lexical em questão é utilizada no estado de Mato Grosso e/ou Mato Grosso do Sul.

No dicionário Houaiss (2001), destacamos o registro das marcas regionais MS e MT no verbete pantaneiro: "B 1. relativo a pântano, esp. Ao Pantanal mato-grossense, ou o que é seu natural ou habitante (espécimes p.) (um p. da gema). MT MS 2. criador de gado; fazendeiro. Adj Zoot. MT MS 4 diz-se de uma raça bovina mato-grossense".

Já Borba (2004) cita apenas Mato Grosso como marca regional para a unidade lexical pantaneiro: "Adj 1 do ou relativo ao Pantanal Mato-grossense: onça pantaneira. S.m 2 quem cria gado no Pantanal Mato-grossense: Como o sertanejo, o pantaneiro é um forte".

Em Aulete (2006) cabe destacar os registros de marcas regionais referentes aos estados do Centro-Oeste: "2. MS MT Aquele que cria gado; Fazendeiro (a). 3. Do pantanal mato-grossense; típico dessa região ou de seu povo". 
Ferreira (2010), por sua vez, registra a seguinte acepção mencionando o estado de Mato Grosso: "adj. (Bras. Mato Grosso) Diz-se de uma raça bovina mato-grossense; s.m. (Bras. Mato Grosso) criador de gado, fazendeiro".

Figueiredo (1899) e Freire (1940) também atribuem à unidade léxica pantaneiro a marca dialetal de Mato Grosso: "Bras. Boi de certa raça de Mato Grosso" (FIGUEIREDO, 1899); "raça de gado cuiabano ou boi de certa raça de Mato Grosso" (FREIRE, 1940).

Além da menção aos estados brasileiros citados nos dicionários gerais, verificamos que as obras regionais também situam as localidades do Centro-Oeste como espaço de utilização da unidade léxica pantaneiro: Souza (1939): "variedade de gado vacum próprio do pantanal de Mato Grosso"; Ortêncio (1983): "Pantaneiro - Variedade de gado bovino, característico da zona do Pantanal, em Mato Grosso".

É possível observar, em alguns dos dicionários citados neste trabalho, a identificação da abreviatura Bras. como um brasileirismo:

Sob esse olhar, podemos conceber o brasileirismo tanto como os fatos linguísticos característicos da variante brasileira em oposição à européia, como aquelas marcas linguísticas regionais que se opõem à norma tomada como padrão nacional. Nesta última acepção, brasileirismo equivale a regionalismo (ISQUERDO, 2003, p. 168).

Dessa forma, ao analisarmos os fragmentos selecionados dos dicionários, ficou evidente o registro da marca de uso diatópico em Mato Grosso e em Mato Grosso do Sul nas acepções atribuídas à unidade lexical pantaneiro nas obras consultadas.

Por sua vez, nos diferentes dicionários gerais estudados, observamos que ora as definições contemplam o animal ora o homem da região. Situação diferente ocorre nos dicionários regionais consultados, que fazem referência apenas ao animal da região, exceto Souza (1939), que define a unidade lexical pantaneiro como designação do homem e do animal:

Com êste nome se designa uma variedade de gado vacum próprio do pantanal de Mato

Grosso, registrando-o Cândido de Figueiredo. Encontramo-lo, porém, empregado no sentido de criador da mesma região, fazendeiro, num artigo de A. de P. Leonardo Pereira, publicado no O Jornal de 23 de setembro de 1928 (SOUZA, 1939, p. 237).

De acordo com os dicionários consultados, é possível afirmar que o item lexical pantaneiro para nomear o animal, sobretudo o bovino, de uma determinada região localizada entre os atuais estados de Mato Grosso e Mato Grosso do Sul é mais antiga (considerando a cronologia da publicação dos dicionários), do que a utilização dessa unidade léxica para designar o homem das mesmas localidades.

Além disso, é possível observar que não há um marco cronológico, no que tange à utilização da unidade léxica pantaneiro para tratar do peão propriamente dito, já que há registros em periódico de 1928, citado em Souza (1939), e depois, apenas nos dicionários gerais contemporâneos. Provavelmente, a designação para o homem surgiu da necessidade de nomear o ser humano que trabalhava com a lida do gado em uma região distante dos grandes centros e com aspectos físico-geográficos particulares. 


\subsection{A unidade lexical pantaneiro em função adjetiva e substantiva}

Em relação às informações lexicográficas registradas nos dicionários gerais, acrescenta-se que a unidade lexical pantaneiro, de acordo com as acepções apresentadas, ora funciona como adjetivo ora como substantivo. Os quadros 5 e 6 , que seguem, detalham essas informações gramaticais registradas nos dicionários gerais.

Quadro 5. A unidade lexical pantaneiro em função de adjetivo

\begin{tabular}{|l|l|l|l|}
\hline \multicolumn{1}{|c|}{ Houaiss (2001) } & \multicolumn{2}{|c|}{ Borba (2004) } & \multicolumn{2}{|c|}{ Aulete (2006) } & \multicolumn{1}{c|}{ Ferreira (2010) } \\
\hline "Relativo a pântano, "Do ou relativo ao & "Do pantanal mato- & "Diz-se de uma raça \\
esp. ao Pantanal mato- & Pantanal mato- & grossense; típico dessa & bovina \\
grossense, ou o que é & grossense: roça & região ou de seu povo". & grossense". \\
seu natural ou habitante & pantaneira". & & \\
(espécimes p.) (um p. & & & \\
da gema)". & & & \\
\hline
\end{tabular}

Quadro 6. A unidade lexical pantaneiro em função de substantivo

\begin{tabular}{|l|l|l|l|}
\hline \multicolumn{1}{|c|}{ Houaiss (2001) } & \multicolumn{1}{|c|}{ Borba (2004) } & \multicolumn{1}{|c|}{ Aulete (2006) } & \multicolumn{1}{c|}{ Ferreira (2010) } \\
\hline $\begin{array}{l}\text { "Criador de gado; } \\
\text { fazendeiro". }\end{array}$ & $\begin{array}{l}\text { "Quem cria gado no } \\
\text { Pantanal "Indivíduo que nasceu } \\
\text { grossense: Como o } \\
\text { sertanejo, o pantaneiro } \\
\text { eu vive no Pantanal". }\end{array}$ & $\begin{array}{l}\text { gador de } \\
\text { fazendeiro". }\end{array}$ & \\
& é um forte". & & \\
\hline
\end{tabular}

De acordo com os quadros 5 e 6, observamos, em ambas as funções gramaticais atribuídas à unidade léxica pantaneiro, a marca da região e, também, a relação entre o trabalho característico da localidade com o homem pantaneiro ou com o que é próprio do ambiente. Além disso, há a observação de que a unidade lexical pantaneiro, normalmente em função adjetiva, aponta para as características da região, enquanto substantivo designa o ser vivo que o caracteriza (homem/animal).

\subsection{Marcas de julgamento sobre o homem pantaneiro}

Cabe ressaltar ainda uma acepção que se destaca das demais, por apresentar julgamento de valor. Observe o fragmento: "BEI - indivíduo ocioso e dado a vulgaridades e gracejos" (HOUAISS, 2001). Cabe assinalar que essa definição se confirma por meio do estudo realizado por Câmara $(2007)^{4}$, que versou sobre causos pantaneiros:

As palavras que definiram o pantaneiro, com as quais Barros deparou-se na Delta Larousse, encontram respaldo também no dicionário do velho Houaiss, que, entre outras definições, fala de um "indivíduo ocioso dado a vulgaridades e gracejos" (Houaiss, 2001: 2.119). O conceito desses estudiosos das palavras deve ter explicação no fato de ser o trabalho do pantaneiro, ao contrário do dos operários que, por sina, enfrentam a lida em lugares onde o "progresso" já se instalou proporcionador de tempo para conversar e conviver. O tempo que sobra para o pantaneiro descansar, que costumeiramente chamamos de ócio, é o momento de tomar o tereré e contar os causos. A imaginação que passeia por essas rodas de conversa conduz a um repertório de

4 Tese de Doutorado: Os causos: uma poética pantaneira, produzida por Ricardo Pieretti Câmara e defendida em 2007, na Universidade Autônoma de Barcelona. 
histórias, inventadas, escutadas ou vividas, as quais, quase sempre, são ligadas ao ambiente natural em que esse povo vive: o Pantanal (CÂMARA, 2007, p. 02).

Além disso, a acepção registrada por Houaiss (2001) favorece a construção de um estereótipo, no que se refere à figura do pantaneiro que, como explicitado por Câmara (2007), é 'construído' pelas características particulares do meio em que vive e de seus hábitos de lazer baseados em atividades simples e cotidianas, sendo totalmente desprovido de ambições consumistas ou modernas.

\subsection{Relações homem/ambiente}

A simbiose existente entre o pantaneiro e o que é próprio do Pantanal, assinalada nos dicionários citados, também é perceptível nos estudos apresentados pela estudiosa Albana Xavier Nogueira, sobre essa temática. Tomando como referência os estudos de Sapir (1969), reforçamos que as influências sofridas pela língua podem ser de caráter ambiental e caráter social. Os fatores físicos referem-se a:

[...] aspectos geográficos, como a topografia da região (costa, vale, planície, chapada ou montanha) clima e regime de chuvas, bem como o que se pode chamar a base econômica da vida humana, expressão em que se incluem a fauna, a flora e os recursos minerais do solo (SAPIR, 1969, p. 44).

Os fatores sociais, por sua vez, "se estendem às várias forças da sociedade que modelam a vida e o pensamento de cada indivíduo" (SAPIR, 1969, p. 44). Verificamos que, no caso da cultura pantaneira, ambos os fatores atuam sobremaneira na manutenção dos costumes.

Em relação à cultura pantaneira, é preciso acrescentar que a figura do peão atuando na lida do gado produz uma significação especial para os habitantes da região já que é uma das formas de sustento da população. Ao tratar dessa figuração, cabe aqui a posição de Sapir (1969, p. 45):

A mera existência, por exemplo, de uma espécie animal no ambiente físico de um povo não basta para fazer surgir um símbolo lingüístico correspondente. É preciso que o animal seja conhecido pelos membros do grupo em geral e que eles tenham nele algum interesse, por mínimo que seja, antes da língua da comunidade ser levada a reportar-se a esse elemento particular físico.

A importância do homem pantaneiro, tanto quanto a do animal, é extremamente importante para a manutenção da cultura nessas localidades de difícil acesso e de vida precária. Em síntese, a análise da unidade lexical pantaneiro evidenciou aspectos culturais tanto sobre a região quanto acerca do seu morador. Todavia, Nogueira (2002, p. 20) informa que

[...] para conhecer o homem pantaneiro, para procurar entender suas práticas simbólicas, seu misticismo, senso de humor, imaginação fértil, sobretudo para inventar mentiras fantásticas, sua miséria, riquezas, espírito contemporizador, é necessário descer o Pantanal, como se diz comumente. 


\section{Considerações finais}

O estudo em questão se propôs a realizar uma análise léxico-semântica e cultural da unidade léxica pantaneiro utilizando, para isso, obras lexicográficas de caráter geral, antigas, contemporâneas e regionais. Além disso, discorreu sobre as localidades que compõem o pantanal e o próprio processo de nomeação da região com o intuito de subsidiar na análise do item lexical eleito para o estudo. A respeito dos dados obtidos, verificamos que as acepções retratam o vínculo entre a figura do homem típico com a localidade e as relações de trabalho e de pertença de algo ou alguém à região do Pantanal, inclusive ao animal (gado) que habita a região.

Quanto à unidade lexical pantaneiro, acreditamos que não há como confirmar sua perpetuação e/ou extinção em momentos posteriores, no entanto, e do mesmo modo, acreditamos que sua presença se dará sempre que se fizer referência à região do Pantanal, bem como aos costumes de seus habitantes, pois a lexia também designa essa população.

Entre outros objetivos, este artigo também buscou salientar a importância do homem pantaneiro e de seu habitat, figura que vem sendo referenciada desde o trabalho pioneiro A linguagem do homem pantaneiro (NOGUEIRA, 1989).

Quanto à estreita ligação existente entre esse homem típico e a localidade é importante exaltar a riqueza e a peculiaridade do falar do homem simples, que vive na lida com o gado e com os afazeres do campo na região, que possui personalidade nos seus hábitos e na sua alimentação e nomina, de forma original, a realidade que o circunda, uma realidade formada, ora pela lida do gado, ora pelas verdes pastagens, ora coberta por água. Essas considerações convergem para a afirmação de Cardoso (2010, p. 15), ao ressaltar a relação da fala do homem ao ambiente:

[...] o espaço geográfico evidencia a particularidade de cada terra, exibindo a variedade que a língua assume de uma região para outra, como forma de responder à diversidade cultural, à natureza da formação demográfica da área, à própria base linguística preexistente e à interferência de outras línguas que se tenham feito presentes naquele espaço no curso de sua história.

\section{REFERÊNCIAS}

ACADEMIA BRASILEIRA DE LETRAS. VOLP - Vocabulário Ortográfico da Língua Portuguesa. Disponível em: <http://www.academia.org.br/nossa-lingua/busca-novocabulario>.

AULETE, C. Dicionário Contemporâneo da Língua Portuguesa. Versão eletrônica. Rio de Janeiro: Editora Lexikon, 2006.

BORBA, F. Dicionário UNESP do Português Contemporâneo. Editora UNESP, 2004. $470 \mathrm{p}$.

BLUTEAU, R. Vocabulario portuguez \& latino: áulico, anatômico, architectonico... Coimbra: Collegio das Artes da Companhia de Jesus, 1712-1728.

CÂMARA, R. P. Os causos: uma poética pantaneira. 2007. 586 f. Tese (Doutorado em Humanidades) - Faculdade de Filosofia e Letras, Universidade Autônoma de Barcelona, 
Barcelona.

Disponível

em:

$<$ http $/ /$ www.tdx.cat/bitstream/handle/10803/5293/rpc1de1.pdf.txt?sequence=2 > .

Acesso em: 03 fev 2015.

CARDOSO, S. Geolinguística: Tradição e modernidade. São Paulo: Parábola, 2010. $200 \mathrm{p}$.

COSTA, M de F. História de um país inexistente. O Pantanal entre os séculos XVI e XVIII. São Paulo: Estação Liberdade, Livraria Cosmos Editora, 1999. 277 p.

CUNHA, A. G. da. Dicionário Etimológico Nova Fronteira da Língua Portuguesa. 2. ed. Rio de Janeiro: Nova Fronteira, 1986. 839 p.

HOUAISS, A. Dicionário Eletrônico Houaiss da Língua Portuguesa. Rio de Janeiro: Editora Objetiva, Instituto Antonio Houaiss, 2001.

FERREIRA, A. B. de H. Novo Dicionário Aurélio da Língua Portuguesa. Curitiba: Positivo, 2010. 2272 p.

FIGUEIREDO, C. de. Novo dicionário da Língua Portuguesa. Lisboa: Imprensa Portugal-Brasil, $1899.1348 \mathrm{p}$.

FREIRE, L. Grande e novíssimo dicionário da Língua Portuguesa, v. IV. Rio de Janeiro: A noite Editora, 1940. 4209 p.

GARCIA, D. S. da C. Território e Negócios na 'Era dos Impérios': Os Belgas na Fronteira Oeste do Brasil. Brasilia: Fundação Alexandre de Gusmão, 2009. 360 p.

GUÉRIOS, R. F. M. Dicionário de etimologias da Língua Portuguesa. Curitiba: Ed. Nacional, 1979. 206 p.

ISQUERDO, A. N. Vocabulário do seringueiro: campo léxico da seringa. In: OLIVEIRA, A. M. P. P.; ISQUERDO, A. N. (Org.). As Ciências do Léxico. Lexicologia, Lexicografia e Terminologia. 2. ed. Campo Grande: Editora UFMS, 2001. p. 89-98.

Léxico em tempo e espaço: a questão dos regionalismos. In: MARIN, J. R.; VASCONCELOS, C. A. de (Org.). História, região e identidades. Campo Grande: Editora da UFMS, 2003. p. 165-181.

De Laguna de los Xarayes a Pantanal: mito e realidade impressos na Toponímia. In: SEABRA, M. C. T. C. de (org.). O Léxico em Estudo. Belo Horizonte: UFMG, 2006. p. 119-135.

MARTINS, G. R. Breve painel etno-histórico de Mato Grosso do Sul. Campo Grande: Ed. UFMS, 2002. 98 p.

NOGUEIRA, A. X. A Linguagem do Homem Pantaneiro. 1989. 383f. Tese (Doutorado em Letras) - Universidade Presbiteriana Mackenzie, São Paulo, 1989.

Pantanal: Homem, Cultura. Campo Grande: Ed. UFMS, 2002. 155 p.

ORTÊNCIO, B. Dicionário do Brasil Central. São Paulo: Editora Ática, 1983. 472 p.

PINTO, L. M. da S. Diccionario da Lingua Brasileira. Typographia de Silva, 1832.

SAPIR, E. Linguística como ciência. Rio de Janeiro: Ed. Livraria Acadêmica, 1969. 203 p. 
SILVA, J. dos S. V. da; ABDON, M. de M. Delimitação do Pantanal Brasileiro e suas sub-regiões. In: Pesquisa Agropecuária Brasileira. v. 33. Brasilia/DF: EMBRAPA, 1998. p. 1703-1711.

SILVA, A. de M. Diccionario da lingua portugueza. 2v. Rio de Janeiro: Francisco Alves, 1922. Fac-símile da segunda edição. Lisboa: Typographia Lacérdina, 1813.

SOUZA, C. A. de; LANI, J. L., SOUSA, J. B. de. Origem e Evolução dos Pantanais. In: VI Simpósio Nacional de Geomorfologia/Regional Conference on Geomorphology 4004- 0001... Goiânia, 2006. Disponível em: <http://www.labogef.iesa.ufg.br/links/sinageo/articles/132.pdf>. Acesso em: 03 fev 2014.

SOUZA, B. J. de. Dicionário da Terra da Gente do Brasil. 4. ed. Salvador: Ed. Companhia das Letras, 1939. 432 p.

Recebido em: 05/10/2015

Aprovado em: 15/01/2016 